\title{
Job satisfaction and challenges of working from home during the COVID-19 pandemic: A study in a Swedish academic setting
}

\author{
Fereshteh Ahmadi ${ }^{\mathrm{a}}$, Saeid Zandi ${ }^{\mathrm{b}, *}$, Önver A. Cetrez ${ }^{\mathrm{c}}$ and Sharareh Akhavan ${ }^{\mathrm{a}}$ \\ ${ }^{a}$ Department of Social Work and Criminology, Faculty of Health and Occupational Studies, University of Gävle, \\ Gävle, Sweden \\ ${ }^{\mathrm{b}}$ Department of Counseling, Faculty of Psychology and Education, Allameh Tabataba'i University, Tehran, Iran \\ ${ }^{\mathrm{c}}$ Faculty of Theology, Uppsala University, Uppsala, Sweden
}

Received 13 March 2021

Accepted 18 August 2021

\begin{abstract}
.
BACKGROUND: The COVID-19 pandemic changed the academic world in various ways, and most universities are still closed and continue operating via teleworking.

OBJECTIVE: This study is intended to investigate how university faculty/staff and students in Sweden have coped with the lockdown and working/studying from home during the pandemic.

METHODS: A survey was conducted among 277 women and men working and studying at different universities in Sweden. RESULTS: The results indicate that most $(61 \%)$ respondents were very or somewhat satisfied with the current work-fromhome arrangement. Additionally, they indicate that, overall, almost $30 \%$ were working more than usual due to the pandemic and teleworking. The coping methods having the highest impact on overall job satisfaction were: "thinking about what I can do rather than what I can't do"; "being able to access medical resources and medical services if I need to seek help"; and "having trust in state or health authorities in my country."
\end{abstract}

CONCLUSIONS: The study reveals that Sweden can serve as a good example of how university faculty/staff and students can address the occupational challenges caused by a health pandemic and possible subsequent quarantines.

Keywords: Coping, coronavirus, pandemic, occupational health, telecommuting, teleworking

\section{Introduction}

On 11 March 2020, the World Health Organization (WHO) declared the COVID-19 outbreak a pandemic. Lockdown strategies and public health policies emphasizing social distancing, stay-at-home orders, and individual behavioral change (e.g.,

*Address for correspondence: Saeid Zandi, Department of Counseling, Faculty of Psychology and Education, Allameh Tabataba'i University, Tehran, Iran. E-mail: sa.zandi@atu.ac.ir. mask-wearing, hand-washing, and discouraged facetouching) were employed worldwide to fight the coronavirus [1].

The coronavirus pandemic changed the occupational world and work environments in various ways. Among the groups affected by the COVID-19 crisis are university faculty/staff and students. The pandemic's conditions may have unpleasant effects on the mental health of university faculty/staff and students [2,3]. Research among 505 university students in Bangladesh demonstrated that stress, anxiety, 
and depression had increased during the lockdowns. Moreover, lack of physical exercise and limited or no recreational activity were related to higher levels of stress, anxiety, depression, and post-traumatic symptoms [4]. Another study among 2530 staff and students of a Spanish university found the emergence of moderate to extremely severe scores for stress, anxiety, and depression among participants resulting from their encounter with the pandemic [5].

One major outcome of the pandemic was that university and college faculty/staff and students began working/studying from home. In response to the emergent situation, most universities and colleges worldwide cancelled most campus events, planned work-from-home arrangements, and provided faculty/staff and students with online digital platforms for tele-education and remote teaching. Faculty and students have been trying to adjust to distance education and online teaching platforms worldwide [3, 6]. Research has provided evidence that the key advantages of teleworking from home are increased flexibility and autonomy and that the adverse effects are a possible sense of isolation and lack of separation between home and workplace [7]. Researchers have proposed some recommendations to help homebound students, professors and researchers around the globe for teleworking during the SARS-CoV-2 epidemic [8-10]: creating routines, being organized, having an adequate home office and using office chairs and external monitors, enhancing one's productivity, being responsible, avoiding extreme multitasking, facilitating communication and networking, being balanced, using available computer programs and platforms, being creative with remote teaching, exploring options for remote research, using preventive tele-rehabilitation methods and learning from the challenges.

One of the most relevant and influential theoretical models that may explain the factors that lead to job satisfaction and coping with the challenges of working from home at the time of COVID-19 is the demand-control model [11]. It explains labor stress in terms of the balance between the job's demands and the level of control of the worker over these. From this model, the worker's health or well-being will depend on the balance between the demands of the job and the worker's available resources. The model has been used in several studies related to occupational health and COVID-19 [12-15].

The COVID-19 pandemic reached many European countries in late February and early March 2020. Sweden was one of the few countries that implemented public health interventions without a mandatory lockdown, instead relying on public recommendations and trust in state and public health authorities to reduce the spread of infection. Schools, universities, and other public facilities remained open, and Swedish citizens implemented "teleworking or work from home" policies where possible [16]. At the time of submission of this article, Sweden had 684,961 Coronavirus cases and 13,003 deaths [17]. In response to the second and even third wave of the pandemic and according to the Swedish government and public health authority recommendations, many universities and colleges decided to conduct much of their education digitally. All staff members who could were to work from home. As a general rule, international students have been offered a mix of on-campus and digital studies [18]. Sweden has 40 universities and colleges, meaning that, during the pandemic, many students and faculty/staff were working at home until March 2021, mostly based on distance education. No earlier studies have examined teleworking during a pandemic in Sweden.

The international project "The meaning-making coping with COVID-19" of which this paper is part comprises three parts. The second part focuses on occupational health and, specifically, on the job satisfaction and challenges of working from home at the time of COVID-19 among university staff and students. This paper is confined to addressing the data gathered in Sweden.

\section{Methodology}

A quantitative research design was employed in this study. The authors developed a survey (Appendix) to investigate Swedish university faculty/staff members' and students' satisfaction with working from home and to identify the methods they used most frequently to cope with the challenges of teleworking during the COVID-19 pandemic.

\subsection{Study population and sample recruitment}

The target group for this study was university faculty/staff and students from different universities in Sweden. Most of them are ethnically Swedish, but some are Swedish citizens who were born abroad. According to Statistics Sweden (SCB), in 2019/2020 about 429,000 students were enrolled in universities and colleges in Sweden with faculty/staff members numbering approximately 38,000 , meaning that the 
Table 1

Characteristics of the sample $(n=277)$

\begin{tabular}{llc}
\hline Variable & Variable value & $\%$ \\
\hline Gender & Man & $36 \%$ \\
Age & Woman & $64 \%$ \\
& Younger than 35 years old & $31 \%$ \\
& Between 35 and 49 years old & $32 \%$ \\
Work/Study situation & 50 years or older & $37 \%$ \\
& University & $94 \%$ \\
Country of birth & Senior high school & $6 \%$ \\
& Sweden & $75 \%$ \\
Job/student situation & Other country & $25 \%$ \\
& Full-time employment & $66 \%$ \\
& Part-time employment & $15 \%$ \\
Civil status & Student & $19 \%$ \\
& Married & $50 \%$ \\
& Divorced & $5 \%$ \\
& Engaged & $11 \%$ \\
& Other relationship & $17 \%$ \\
Children & Single & $1 \%$ \\
Place of residence & Children & $64 \%$ \\
& No children & $36 \%$ \\
& Capital & $18 \%$ \\
& Medium-large city & $48 \%$ \\
& Small town close to large city & $23 \%$ \\
& Small town far from large city & $11 \%$ \\
\hline
\end{tabular}

study population is approximately 470,000 people. Some universities in Sweden were selected for study, and from their personnel and student registers, faculty/staff and students were selected for setting up the sampling frame, i.e., the actual list of individuals from which the sample would be drawn. Ideally, the sampling frame should represent the entire target population (and nobody who is not part of it) for random sampling.

Respondents randomly selected from this list were emailed with a link to the web questionnaire. This type of list-based sampling frame with randomly selected respondents represents a type of probability sampling, according to the Sage Handbook of Online Research Methods [19]. A total of 277 women and men studying and working in different universities in Sweden had responded by 30 May 2020, when data gathering ended. In total, 277 questionnaires were included in the analysis. Table 1 shows the demographic characteristics of the study participants.

\subsection{Data collection}

Data collection was done using an open online questionnaire from the University of Gävle and a web-based survey tool from Sunet called Sunet Survey. An information letter was attached to both the emails and the online questionnaire; it covered the research ethics considerations, especially voluntary participation, respondent anonymity, and data usage. To answer the questions in the web survey, the informants first had to give their consent.

\subsection{Measure}

In this article, we did not use the existing scales due to the peculiarities of working from home and also the novelty of the pandemic situations. Given the urgency of studying the topic investigated and the potential applications of the findings, we prepared a questionnaire including items adjusted to a homebound teleworking condition at the time of COVID-19 lockdowns. Four questions were asked (Appendix): the first asked whether the respondent was working more than the contracted hours when working from home (responses, yes/no); the second asked how satisfied the respondent was with working from home (responses ranging from 1 - Very dissatisfied to 5 - Very satisfied); the third asked how the respondent was coping with the challenges of working from home, and included 12 sub-questions (responses ranging from $1-$ Never to 5-Always) with a Cronbach's alpha of 0.748 (which is high). Additionally, a fourth question about general self-reported health was asked (responses ranging from 1 - Poor to 5 - Excellent).

\subsection{Data analysis methods}

We performed various calculations, including descriptive statistics, Pearson's correlation, chisquare analysis, cross tabulations (by gender, i.e., women and men, and age group, i.e., young, middle aged, and older), work/study situation (i.e., full-time, part-time, on-campus student, and distance student), and place of residence (i.e., capital, medium-large city, small town close to a large city, and small town far from a large city). The sample was not weighted to reflect the actual academic staff or student populations it is representative of. The data were analyzed using SPSS Statistics 27.

\subsection{Ethical considerations}

An application for ethical approval was submitted and successfully reviewed by the Swedish Ethical Review Authority (Reg. no. 2020/02368 9). 


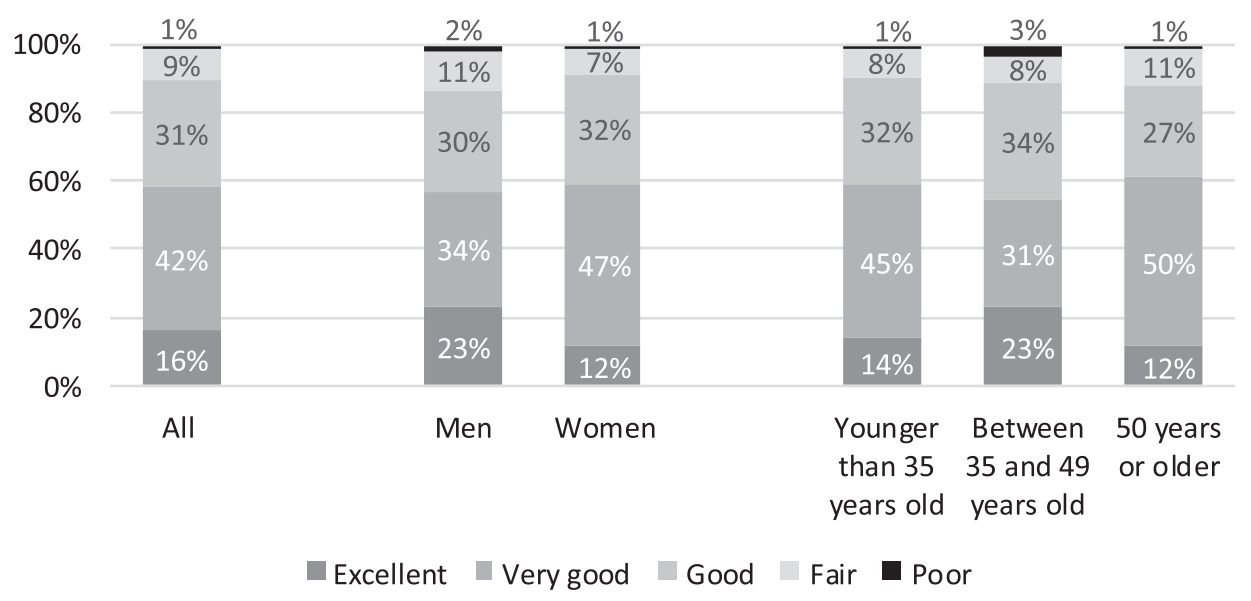

Fig. 1. Self-reported health, by gender and age.

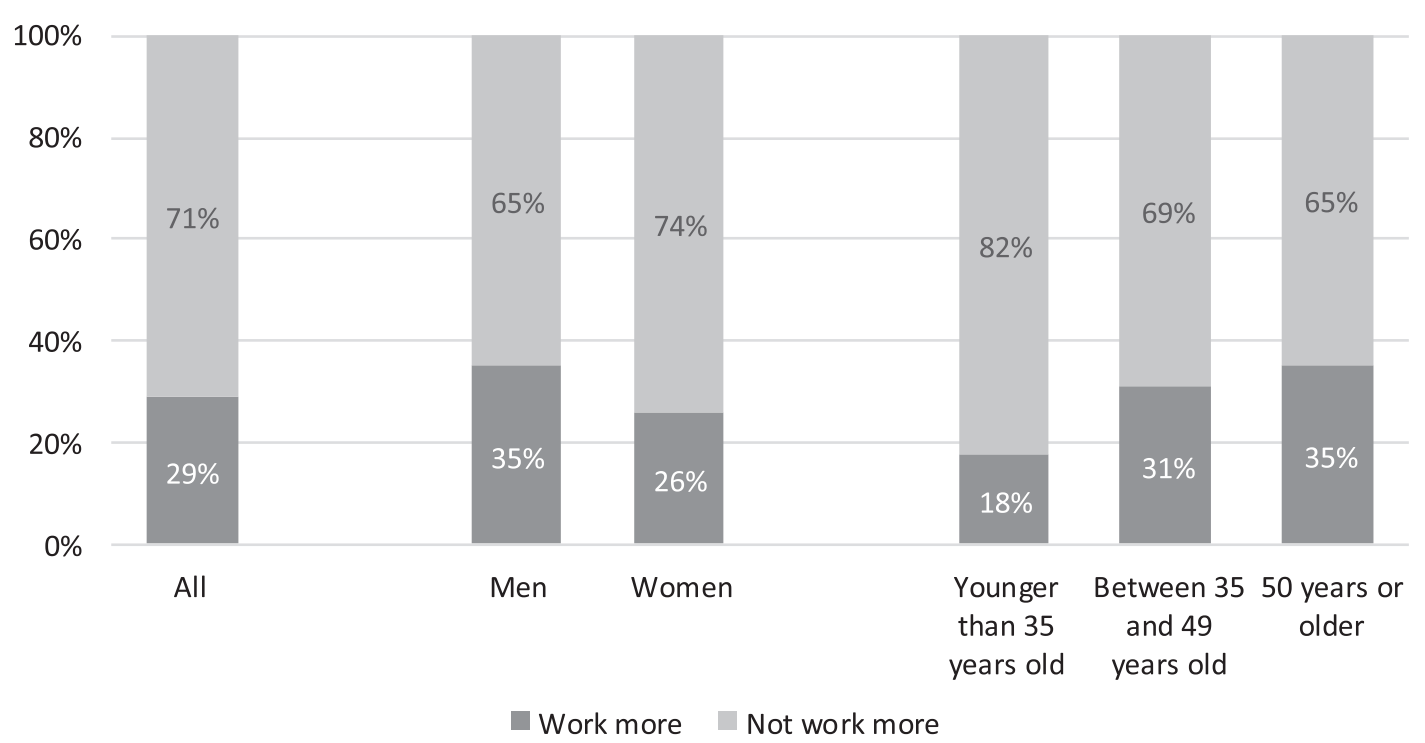

Fig. 2. Perceived teleworking due to COVID-19 crisis versus contracted hours.

\section{Results}

\subsection{Self-reported health}

Figure 1 presents the self-reported health of the university faculty/staff and students in Sweden who participated in this study. Overall, a majority - i.e., $58 \%$ - said that their health was excellent or very good, while another $31 \%$ reported their health to be good, for a total of $89 \%$ who said that their health was at least good. Only one percent reported poor health. Men more often tended to report their health as excellent, i.e., $23 \%$ versus $12 \%$ for women. However, a larger share of women than men believed their health to be excellent or very good, i.e., $59 \%$ versus $57 \%$, respectively. There were only very small differences across ages in the proportions saying that their health was excellent or very good. Analyzing only those saying that their health was excellent, the middle-aged reported themselves to be healthier. Across all groups, about one in ten perceived their health to be no better than fair (Fig. 1).

\subsection{Teleworking and job satisfaction after COVID-19 outbreak}

Figure 2 presents the respondents' perceptions of teleworking hours. The results indicate that three in 


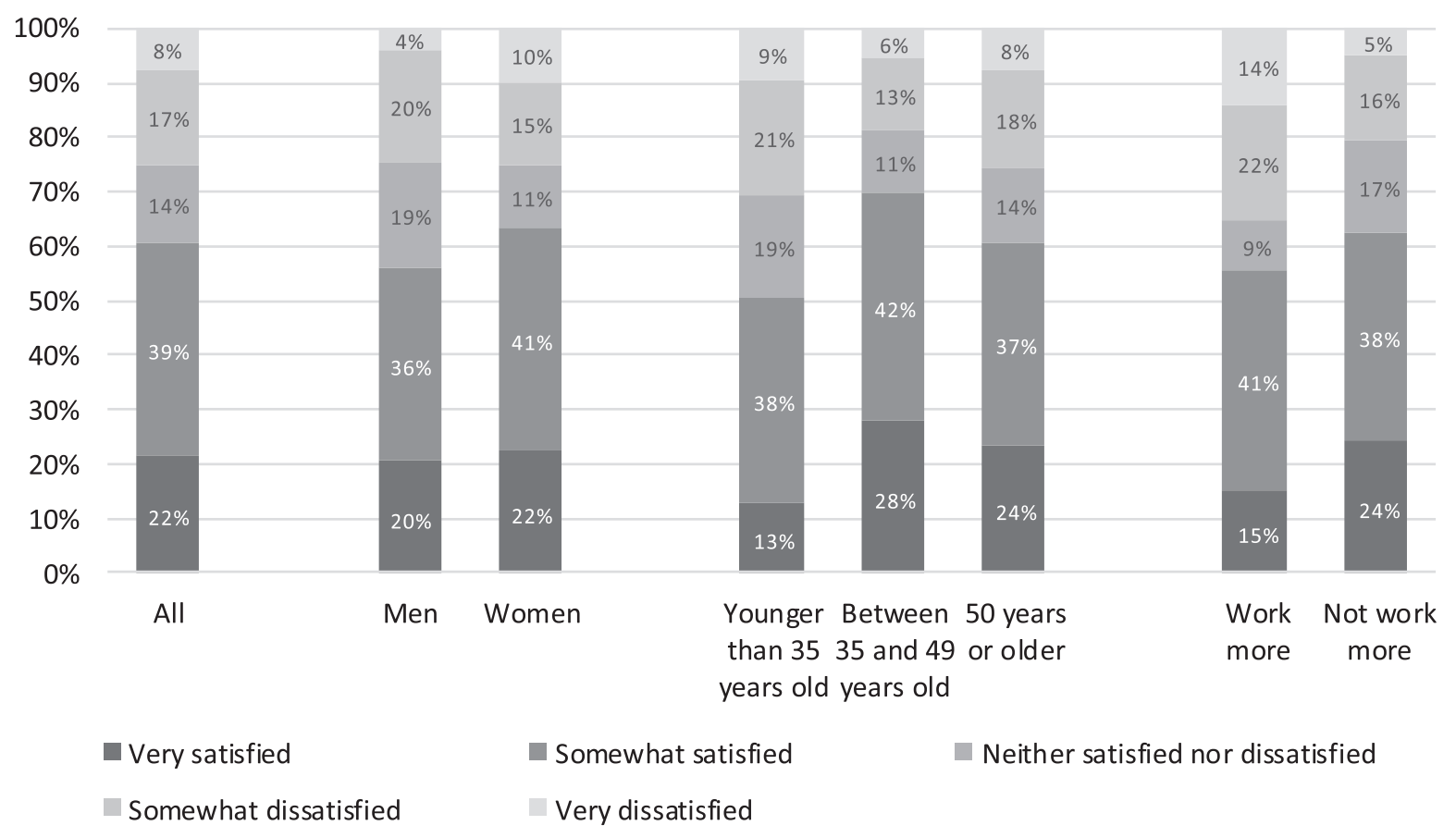

Fig. 3. Level of satisfaction with teleworking.

ten were working more due to the crisis. In particular, men and those over 50 years old worked more when teleworking during the COVID-19 outbreak. Overall, almost $30 \%$ were working more than usual due to the pandemic and teleworking.

Most faculty/staff and students in Sweden who participated in this study were satisfied with teleworking, with most $(61 \%)$ being very or at least somewhat satisfied with working from home. Women $(63 \%)$ tended to be more satisfied with teleworking than were men $(56 \%)$. When comparing the three age groups, the middle-aged were more satisfied than the younger and older groups. Those reporting that they were not working more due to the crisis were also more satisfied (Fig. 3).

\subsection{Coping methods employed to address the challenges of teleworking}

Figure 4 ranks the coping methods used to address the challenges of teleworking during the COVID-19 epidemic. Over $90 \%$ of the study participants used 11 of the 12 coping methods. The only coping method that most did not use was "giving myself a time limit for the daily consumption of news." The four most used coping methods concerned offering kindness to others, maintaining their own health, and feeling solidarity. Most ( $84 \% ; M=4.18, \mathrm{SD}=0.770)$ were often or always "trying to offer kindness or support to the people around them." Another $83 \%$ were "caring for [their] own mental and physical health" ( $M=4.16, \mathrm{SD}=0.798)$. Almost as many thought that "we are all in this together, and with solidarity we can find the best solutions for handling COVID-19" $(M=4.20, \mathrm{SD}=0.997)$. The strategy "trusting state and local authorities" was another coping method used by $77 \%$ of the study participants $(M=3.89, \mathrm{SD}=$ 0.979).

To better understand these 12 methods for coping with the challenges of teleworking during the pandemic, a factor analysis was conducted. Four of the 12 coping methods were often mentioned together, yielding a factor called "trust in authorities and social solidarity." Another four coping methods were grouped to create another factor, "care of one's own health and of close friends." Respondents' results about their health and taking care of close friends were interlinked. A third way of addressing the situation was simply "to keep busy." The fourth factor concerned using "social contacts on social media" as a way of coping with the situation. Those who mentioned having contact with family and friends on social media also mentioned having social media contact with colleagues and friends (Table 2). 


\begin{abstract}
Try providing kindness and support to the people around me Care for my mental and physical health

Believe we are all in this together, and with solidarity we can find the best solutions for handling covid-19

Trust state or local health authorities in my country

Avoid recommendations that are not from public health authorities in my county or from World Health Organisation.

Have social contact with my family and friends through distance tools and social media

Think about what I can do, rather than what I can't

Make sure to have access to medical resources and the health services if I need to seek health care

Read/collect information from Public health authorities in my country or World Health Organisation and keep myself update with public..

Make myself busy with my working day because it makes me feel useful

Have social contacts with my colleagues/classmates through distance tools and other social media
\end{abstract}

Give myself a news time limit for each day

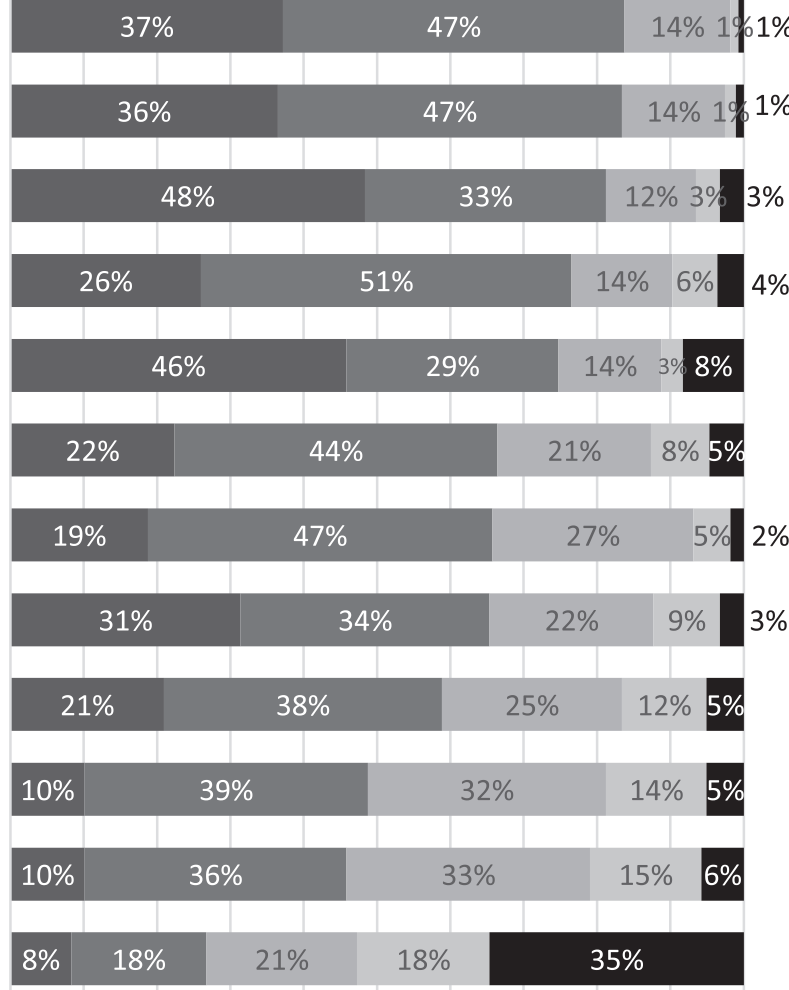

$\begin{array}{lllllllllll}0 \% & 10 \% & 20 \% & 30 \% & 40 \% & 50 \% & 60 \% & 70 \% & 80 \% & 90 \% & 100 \%\end{array}$

\section{Always $\square$ Often $\square$ Sometimes Seldom $\square$ Never}

Fig. 4. Coping methods used to address the challenges of teleworking.

\subsection{Coping methods by gender and age}

Figures 5-8 show the four most frequently used methods for coping with the challenges of teleworking, by gender and age. The figures show that women responded more by offering kindness, that older people took more care of their mental and physical health as well as showing solidarity, and that younger people (and women) trusted state or local health authorities more than did others.

\subsection{The impact of coping methods on job satisfaction}

The coping methods that had the greatest impact on overall satisfaction with working from home during the pandemic are shown in Fig. 9. In this figure, the upper-right area shows the coping methods that had more impact on satisfaction with remote work, whereas the lower-left area shows the coping methods that had less impact on satisfaction with working from home. When all of the methods for coping with the challenges of teleworking during COVID-19 are correlated (using correlation analysis) with overall job satisfaction, we see that "thinking about what I can do rather than what I can't do" had the highest impact on satisfaction with working from home. The second most important method for coping with working from home concerned "being able to access medical resources and medical services if I need to seek help." The third most important method was "having trust in state or health authorities in my country."

The correlation between impact on overall satisfaction with teleworking and coping methods used to deal with the challenges of teleworking is shown in Table 3. There are statistically significant relationships between satisfaction with teleworking and different items such as "Think about what I can do rather than what I can't" (Table 3). Though the correlations are low, a Cronbach's alpha for these sets of statements is high (.742). 
Table 2

Factor analysis of different methods for coping with the challenges of teleworking

\begin{tabular}{|c|c|c|c|c|}
\hline & $\begin{array}{l}\text { 1. Trust in } \\
\text { authorities and } \\
\text { solidarity in } \\
\text { society }\end{array}$ & $\begin{array}{l}\text { 2. Active care } \\
\text { of own health } \\
\text { and near } \\
\text { friends }\end{array}$ & 3. Get busy & $\begin{array}{l}\text { 4. Social } \\
\text { contacts with } \\
\text { social media }\end{array}$ \\
\hline $\begin{array}{l}\text { Read/collect information from Public health } \\
\text { authorities in my country or World Health } \\
\text { Organization and keep myself update with public } \\
\text { health news }\end{array}$ & 0,639 & 0,101 & 0,265 & 0,028 \\
\hline Trust state or local health authorities in my country & 0,796 & 0,030 & $-0,136$ & 0,138 \\
\hline $\begin{array}{l}\text { Avoid recommendations that are not from public } \\
\text { health authorities in my county or from World } \\
\text { Health Organization. }\end{array}$ & 0,541 & 0,228 & $-0,012$ & $-0,105$ \\
\hline $\begin{array}{l}\text { Believe we are all in this together, and with } \\
\text { solidarity we can find the best solutions for } \\
\text { handling COVID-19 }\end{array}$ & 0,714 & 0,221 & 0,159 & 0,166 \\
\hline Think about what I can do, rather than what I can't & 0,184 & 0,507 & 0,440 & $-0,051$ \\
\hline Care for my mental and physical health & 0,050 & 0,823 & 0,021 & 0,101 \\
\hline $\begin{array}{l}\text { Try providing kindness and support to the people } \\
\text { around me }\end{array}$ & 0,201 & 0,751 & 0,181 & 0,119 \\
\hline $\begin{array}{l}\text { Make sure to have access to medical resources and } \\
\text { the health services if I need to seek health care }\end{array}$ & 0,285 & 0,564 & 0,047 & 0,196 \\
\hline $\begin{array}{l}\text { Make myself busy with my working day because it } \\
\text { makes me feel useful }\end{array}$ & 0,179 & 0,124 & 0,750 & 0,100 \\
\hline Give myself a news time limit for each day & $-0,071$ & 0,060 & 0,758 & 0,077 \\
\hline $\begin{array}{l}\text { Have social contacts with my } \\
\text { colleagues/classmates through distance tools and } \\
\text { other social media }\end{array}$ & 0,130 & 0,007 & 0,090 & 0,817 \\
\hline $\begin{array}{l}\text { Have social contact with my family and friends } \\
\text { through distance tools and social media }\end{array}$ & $-0,005$ & 0,309 & 0,068 & 0,713 \\
\hline
\end{tabular}

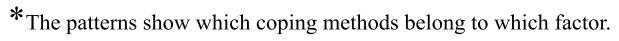

\section{Discussion}

The coronavirus pandemic has contributed to an increase in the proportion of people working from home. There have been differences among countries in teleworking during the pandemic due to different levels of affinity for technology, availability and quality of technological infrastructure, management 


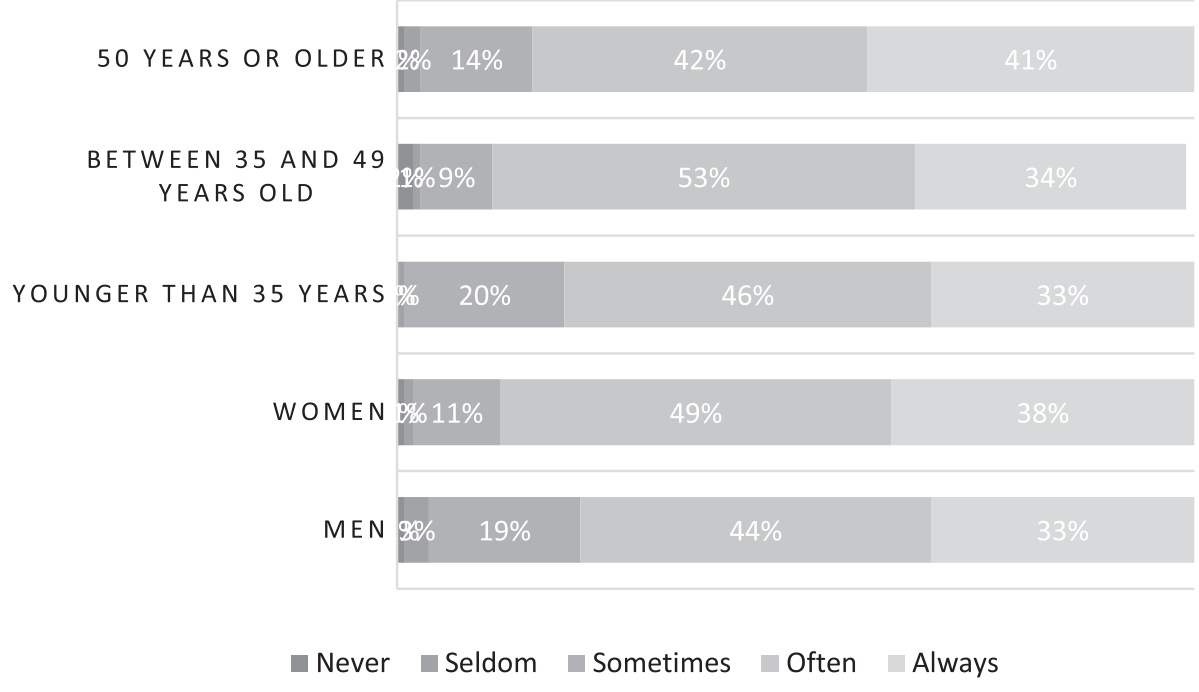

Fig. 5. I try offering kindness and support to the people around me.

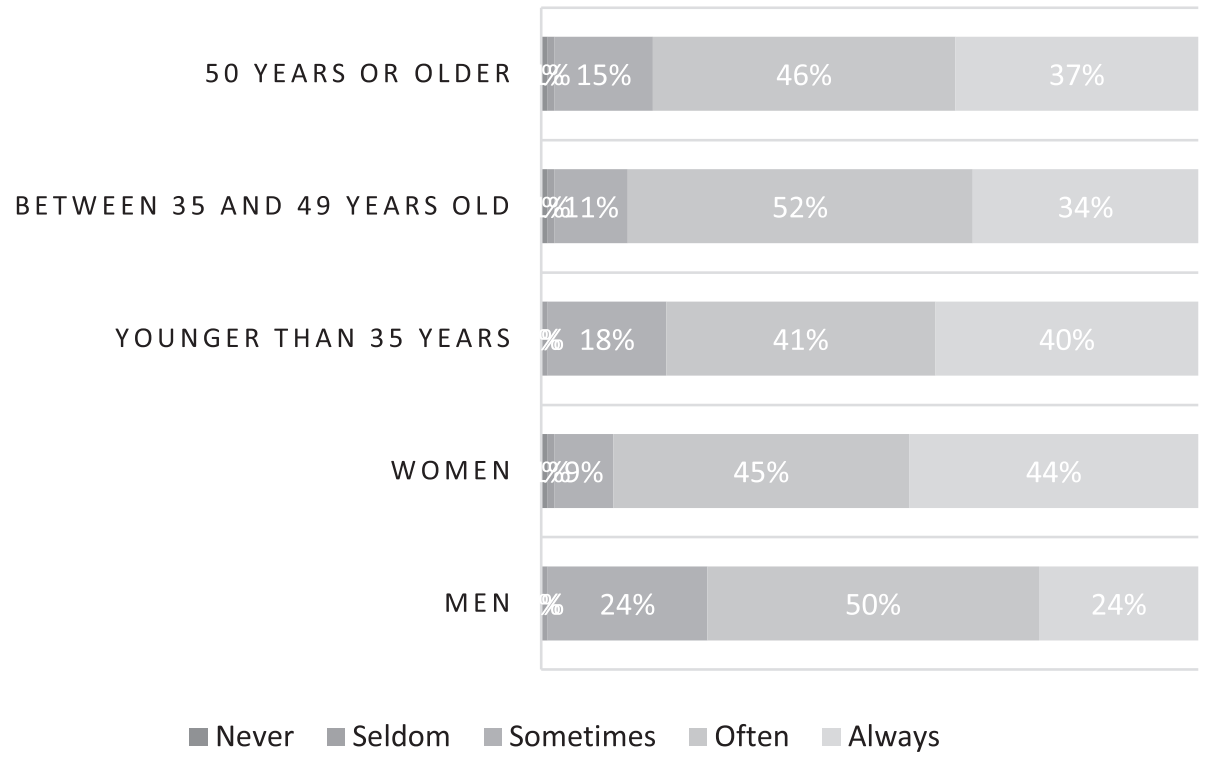

Fig. 6. I care for my mental and physical health.

culture and drive for higher productivity within companies, and employee needs for spatial and temporal flexibility to balance work demands with family commitments and other personal responsibilities [20]. This study examined Swedish academic faculty, staff, and student satisfaction with teleworking during the COVID-19 pandemic. Furthermore, the study attempted to identify how university faculty/staff members and students coped with the challenges of lockdown and working/studying from home during the pandemic. Most respondents were women over age 35, highly educated, employed full time, married, and living in a medium-large city in Sweden. They reported their health to be excellent or very good.

\subsection{Teleworking and job satisfaction during the COVID-19 outbreak}

The results indicate that most $(61 \%)$ respondents were very or somewhat satisfied with the current 
50 YEARS OR OLDER

BETWEEN 35 AND 49 YEARS OLD

YOUNGER THAN 35 YEARS

WOMEN

MEN

never $\quad$ Seldom

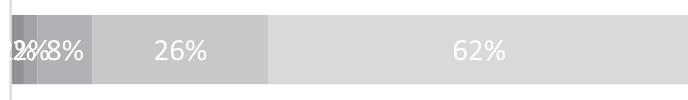

\section{$6 \% 4 \% 12 \%$}

$38 \%$

$40 \%$

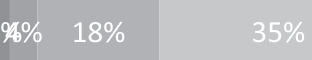

$35 \%$

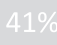

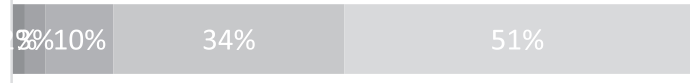

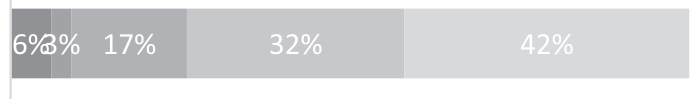

Seldom Sometimes $\square$ Often $\square$ Always

Fig. 7. I believe we are all in this together, and with solidarity.

50 YEARS OR OLDER

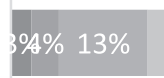

$55 \%$

$25 \%$

BETWEEN 35 AND 49 YEARS OLD

$7 \% 4 \% 12 \%$

$54 \%$

$22 \%$

YOUNGER THAN 35 YEARS

$\% 11 \% \quad 16 \%$

$41 \%$

$31 \%$

WOMEN

$37 \% 10 \%$

$50 \%$

$30 \%$

MEN

$5 \% 5 \% \quad 19 \%$

$51 \%$

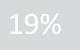

Never Seldom Sometimes Often Always

Fig. 8. I trust state or local health authorities in my country.

work-from-home arrangement, which can be due to balance between the demands of the job and respondents' available resources [11]. Additionally, they indicate that overall almost $30 \%$ of respondents were working more than usual due to the pandemic and teleworking. In another study of the effects of the COVID-19 pandemic on distance work and how individuals were affected by this, $65 \%$ of respondents stated that telework negatively affected well-being in the workplace; also, 55\% stated that distance work had negative consequences for team spirit [21].
Although several studies found overall increased employee satisfaction with their jobs during the pandemic $[22,23]$, there have also been some reports of teleworking leading to a tendency to work longer hours. This could be because time usually spent travelling to the workplace was replaced with work tasks and/or because of changes in work plans and routines. Teleworking, in general, may lead to longer working hours and even to working more during evenings and weekends $[24,25]$. Specific research on working hours and teleworking during the COVID-19 


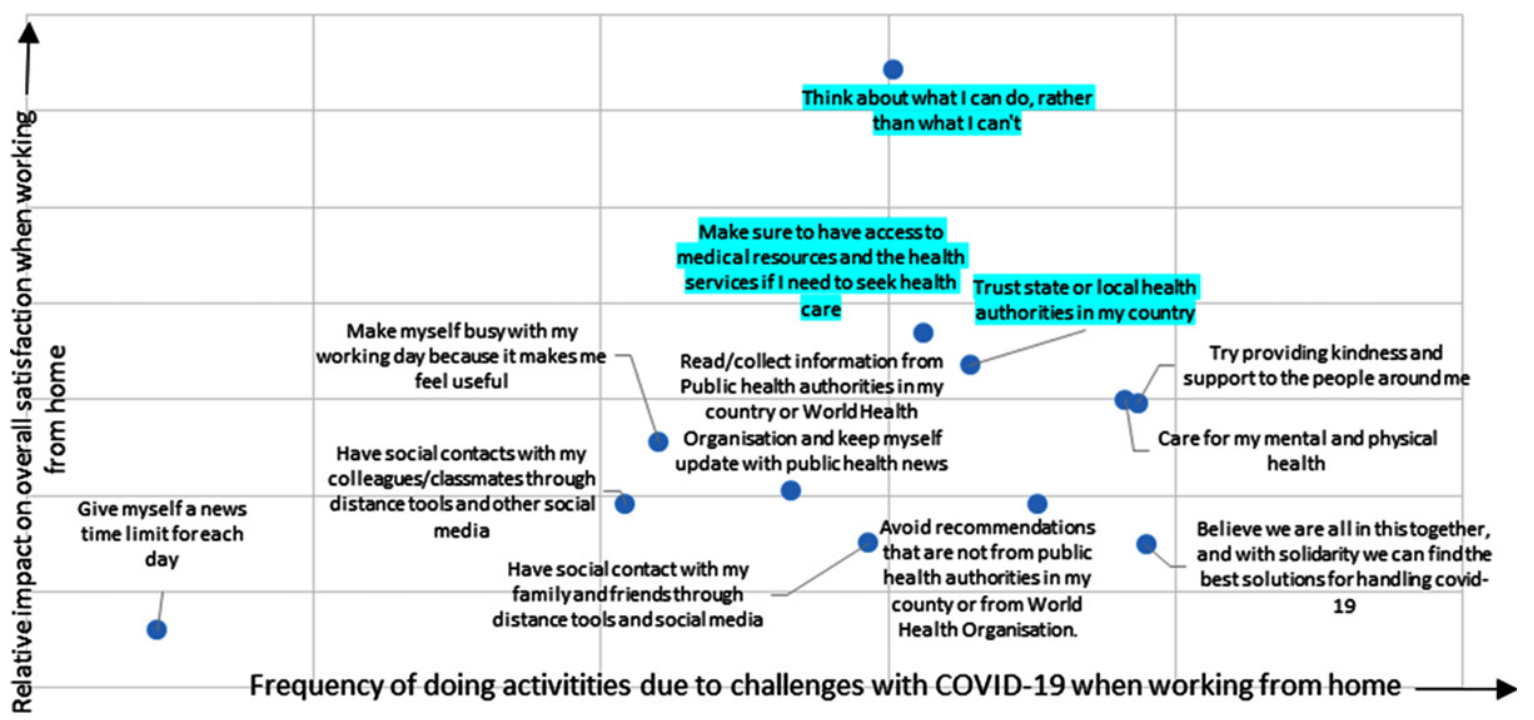

Fig. 9. Relative impact of coping methods on satisfaction with working from home. ${ }^{*}$ The highlight shows the three methods that have relatively most impact on overall satisfaction.

pandemic has shown that employees worked extra hours or worked in their free time to meet work demands [26, 27], which may increase psychosocial risks associated with unstructured working time [28].

The present results indicate that when comparing the three age groups of respondents, the middle-aged were more satisfied with the current work-fromhome arrangement than the younger and older groups. This could be because they are at an age when they have children or other dependents at home and they consequently need to find time for non-work tasks in their working day. Teleworking makes it possible to break up the working day into smaller segments, interspersed with breaks for childcare, household chores, home-schooling, etc. [29], which may lead to increased satisfaction with teleworking. This might be explained through the Karasek's job demand-control-support model [11] which argues that the experience of stress (stress outcomes) is a consequence of the interaction between the stressor (e.g., job demands), the individual's perception of their control over the stressor (e.g., job control), and social support. Previous studies found that teleworking provides staff with autonomy and flexibility [7] and allows work to be combined with household chores and childcare, ultimately improving the work-family balance [30]. However, other researchers have noted that the combination of increased family and work demands makes for a "perfect storm" that can drastically escalate work-family conflict [31].

\subsection{Coping methods used to face the challenges of teleworking during the coronavirus crisis}

University faculty/staff and students in Sweden mostly used four ways to cope with the challenges of teleworking during the pandemic: "caring for my own mental and physical health"; "trying to offer kindness or support to the people around me"; "with solidarity we can find the best solutions for handling COVID19"; and "trusting in state and local authorities." The only coping method that most did not use was "giving myself a time limit for the daily consumption of news."

Respondents replied that "caring for [their] own mental and physical health" was one method used to address the challenges of teleworking. Research on other university staff working from home has shown that this period of teleworking may have consequences for the musculoskeletal system [9, 32], pain, well-being, stress, depression, fatigue, quality of life, strain, and happiness [33].

Prolonged pandemic teleworking may increase feelings of isolation and social loneliness. In this period, "solidarity" and "offering kindness or support" were methods used by Swedish university faculty/staff and students to address the challenges of teleworking. An article entitled "Solidarity in the time of COVID-19?" described solidarity as "the collective good of being bound together in order to provide mutual assistance through what we perceive as some form of common interest" [34]. Despite the dominant 


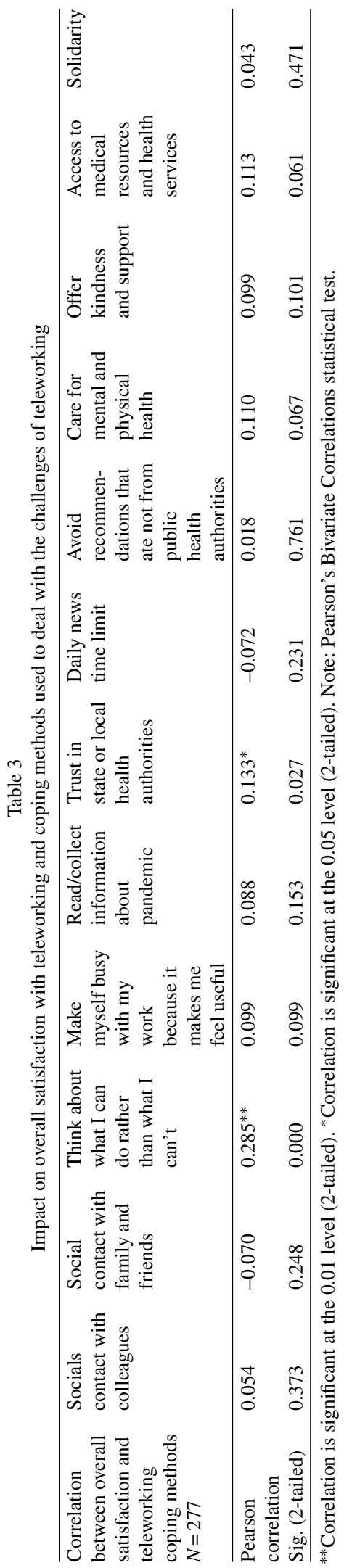

individualistic view of human beings as free, independent, responsible, and self-governing, there exists a spirit of social solidarity in Swedish ways of thinking according to which everyone should contribute her/his share to create a secure social system [35]. What is emphasized is improving the human condition. To allow people to "carry their own weight" and be the architects of their own happiness, the welfare system must enable people to live alone and be independent of family and relatives. The welfare system should provide each person with the means needed for basic security regardless of personal wealth or kinship. According to Barinaga, that Swedes accept such a high level of taxation is an expression of their social concern [36]. To this we can add Swedes' enthusiasm for helping people around the world who are victims of injustice or catastrophes such as war, earthquakes, and starvation. Among other matters, the role of social democracy in shaping Swedish culture has greatly influenced the development of this enthusiasm. Herlitz noted: "Social democracy has greatly influenced the shape of Swedish culture today. One contribution it has made has been to take strong measures to protect the weak, the frail, the poor and the vulnerable" [35]. This structured and abstract solidarity with others may demonstrate the tendency toward empathy and altruism in Swedish culture. Seen in this light, we have no difficulty understanding why being a good person and fulfilling one's responsibility as a human being may be used as a coping method by Swedes.

Another important method used to address the challenges of teleworking was "trust in authorities." This result is in line with the Swedish way of tackling the pandemic. Unlike other European countries, Swedish public health authorities avoided authoritarian measures and followed a strategy based on trust between authorities and the people, empowering the citizens, and focusing on protecting vulnerable groups. As studies show [37-39], trust in authorities and general social trust have historically been high in Scandinavian countries. As Helsingen [39] noted, and according to the World Value Surveys and the Quality of Government Institute, in Scandinavia around $70 \%$ of citizens say that they generally trust other people; the comparable share is about $40 \%$ in countries such as Germany, Canada, and the USA, less than 30\% in Mediterranean countries, and even lower in many countries in Eastern Europe and the Balkans. A survey study of 3,508 individuals (Norway, 3,000; Sweden, 508) found that Swedes have more trust in the authorities than do Norwegians 
(Norway, 17\%; Sweden, 37\%). The study showed that $61 \%$ of Swedish people have high or very high trust and $81 \%$ some trust in their government. When it comes to health authorities, $50 \%$ of Swedish people have very high, $75 \%$ very high and high, and $87 \%$ some trust (i.e., medium, high, and very high). The survey also showed that preventive measures have been applied successfully through advice based on mutual trust between authorities and the people in Sweden [39]. Both "solidarity" (mostly among women and those over age 50) and "trust" (mostly among women and those over age 35) have been used by Swedish university faculty/staff and students as methods to address the challenges of teleworking in a time of global pandemic.

Recent Iranian research [Authors, unpublished data] showed that the coping methods with the greatest impact on academics' and students overall job satisfaction in a teleworking context were "keeping myself busy during my working day because it makes me feel useful" and "thinking about what I can do rather than what I can't do." Likewise, in the present study, when all the methods for coping with the challenges of teleworking during COVID-19 were correlated with overall job satisfaction, we saw that "thinking about what I can do rather than what I can't do" had the highest impact on satisfaction with working from home. This coping method can be a way to manage stress in a time of teleworking during the pandemic.

The coronavirus pandemic is an acute stressor, affecting the world's population. The pandemic has increased several occupational stressors, such as workload and working hours. The job demandsresources model can illustrate how to address high workload demands when one has little control over one's work during the coronavirus pandemic. Reducing workload during a pandemic may not be an option for university faculty/staff and students, but it may be possible to target other stressors such as perceived lack of control [40]. "Thinking about what I can do rather than what I can't do" may serve as a stress management method by which people can gain control over occupational stressors.

\section{Conclusion}

Due to the coronavirus pandemic, over 3.4 billion people in 84 countries have been largely confined to their homes since late March 2020, meaning that millions of working people have been temporarily exposed to teleworking. Assessing how the health risks and benefits of telework have been affected by its sudden, large-scale uptake in the context of COVID19 is central to preserving occupational health. This study helps improve scientific knowledge of teleworking by developing and disseminating knowledge gained during this crisis to create even safer and healthier workplaces. University managements have a role to play in minimizing the unintended health consequences of pandemic-control measures. Academics themselves are also responsible in ameliorating their own occupational health during the current COVID-19 pandemic, and beyond.

\subsection{Strengths and limitations of this study}

The strengths of this study are attributable to the methods used to establish trustworthiness, including validity, reliability, and objectivity. Validation was done by running a pilot test, checking for internal consistency, and finally revising the questionnaire items. The reliability or accuracy of the instrument was checked using Cronbach's alpha. Objectivity, which is the ability to capture a situation accurately, without the influence of prejudice or bias, was strengthened by the engagement in the research process of four authors from different scientific disciplines and countries of origin. One limitation of this study is the sample size, which may reduce the explanatory power of the study and the generalizability of the findings to other populations and settings. Another limitation is the study's cross-sectional design; a longitudinal study design would be more useful in assessing the long-term maintenance of job/study satisfaction and the coping methods used by academics and students. Additionally, the survey was based on the perceptions of the individuals. Subjective perceptions regarding the organization of teleworking have the potential for bias as they relate to the adverse impact of being home and COVID-19. The responds to the questions in the questionnaire could be affected by the pandemic related (fear of infection, fear of job loss) stressors rather than only to the stress of moving to a home office.

\section{Acknowledgments}

We wish to express our gratitude to all the Swedish participants. We greatly appreciate the funding provided by the University of Gävle, Sweden. 


\section{Conflict of interest}

The authors report no conflicts of interest.

\section{Supplementary materials}

The appendix is available from https://dx.doi.org/ 10.3233/WOR-210442.

\section{References}

[1] Lunn PD, Belton CA, Lavin C, McGowan FP, Timmons S, Robertson DA. Using Behavioral Science to help fight the Coronavirus. J Behav Public Adm. 2020;3(1).

[2] Al-Rabiaah A, Temsah MH, Al-Eyadhy AA, Hasan GM, Al-Zamil F, Al-Subaie S, et al. Middle East Respiratory Syndrome-Corona Virus (MERS-CoV) associated stress among medical students at a university teaching hospital in Saudi Arabia. J Infect Public Health. 2020;13(5):687-91.

[3] Araújo FJ de O, de Lima LSA, Cidade PIM, Nobre CB, Neto MLR. Impact Of Sars-Cov-2 And Its Reverberation In Global Higher Education And Mental Health. Psychiatry Res. 2020;288:112977.

[4] Khan AH, Sultana MS, Hossain S, Hasan MT, Ahmed HU, Sikder MT. The impact of COVID-19 pandemic on mental health \& wellbeing among home-quarantined Bangladeshi students: A cross-sectional pilot study. J Affect Disord. 2020;277:121-8.

[5] Odriozola-González P, Planchuelo-Gómez Á, Irurtia MJ, de Luis-García R. Psychological effects of the COVID-19 outbreak and lockdown among students and workers of a Spanish university. Psychiatry Res. 2020;290.

[6] Sahu P. Closure of Universities Due to Coronavirus Disease 2019 (COVID-19): Impact on Education and Mental Health of Students and Academic Staff. Cureus. 2020;12(4).

[7] Harpaz I. Advantages and disadvantages of telecommuting for the individual, organization and society. Work Study. 2002;51(2):74-80.

[8] Lopez-Leon S, Forero DiA, Ruiz-DIáz P. Recommendations for working from home during the COVID-19 pandemic (and beyond). Work. 2020;66(2):371-5.

[9] Gerding T, Syck M, Daniel D, Naylor J, Kotowski SE, Gillespie GL, Freeman AM, Huston TR, Davis KG. An assessment of ergonomic issues in the home offices of university employees sent home due to the COVID-19 pandemic. Work. 2021;68(4):981-92. doi: 10.3233/WOR205294.

[10] Kayabınar E, Kayabınar B, Önal B, Zengin HY, Köse N. The musculoskeletal problems and psychosocial status of teachers giving online education during the COVID-19 pandemic and preventive telerehabilitation for musculoskeletal problems. Work. 2021;68(1):33-43. doi: 10.3233/WOR-203357.

[11] Karasek RA. Job demands, job decision latitude, and mental strain: Implications for job redesign. Adm Sci Q. 1979;24(2):285-308.

[12] Shacham M, Hamama-Raz Y, Kolerman R, Mijiritsky O, Ben-Ezra M, Mijiritsky E. COVID-19 Factors and Psychological Factors Associated with Elevated Psychological Distress among Dentists and Dental Hygienists in Israel.
Int J Environ Res Public Health. 2020;17(8):2900. doi: 10.3390/ijerph17082900

[13] Ramaci T, Barattucci M, Ledda C, Rapisarda V. Social Stigma during COVID-19 and its Impact on HCWs Outcomes. Sustainability. 2020;12(9):3834. doi: 10.3390/su 12093834

[14] Norful AA, Rosenfeld A, Schroeder K, Travers JL, Aliyu S. Primary drivers and psychological manifestations of stress in frontline healthcare workforce during the initial COVID19 outbreak in the United States. Gen Hosp Psychiatry. 2021;69:20-6. doi: 10.1016/j.genhosppsych.2021.01.001.

[15] Soto-Rubio A, Giménez-Espert MDC, Prado-Gascó V. Effect of Emotional Intelligence and Psychosocial Risks on Burnout, Job Satisfaction, and Nurses' Health during the COVID-19 Pandemic. Int J Environ Res Public Health. 2020;17(21):7998. doi: 10.3390/ijerph17217998.

[16] Sjödin H, Johansson AF, Brännström Å, Farooq Z, Kriit HK, Wilder-Smith A, et al. COVID-19 healthcare demand and mortality in Sweden in response to non-pharmaceutical mitigation and suppression scenarios. Int $\mathrm{J}$ Epidemiol. 2020;49(5):1443-53.

[17] Worldometer. Sweden [Internet]. 2021. Available from: https://www.worldometers.info/coronavirus/country/sweden

[18] The University and COVID-19 [Internet]. Available from: https://www.gu.se/en/news-and-events/the-university-andcovid-19.

[19] Fielding N, Lee R, Blank G, Fricker RD. Sampling Methods for Web and E-mail Surveys. In: The SAGE Handbook of Online Research Methods. SAGE Publications, Ltd; 2012. p. $195-216$.

[20] Eurofound. Living, working and COVID-19, COVID-19 series. Luxembourg: Publications Office of the European Union; 2020.

[21] Tele2. New survey from Tele2 and Kantar Sifo: teleworking will increase by $250 \%$ after the pandemic [Internet]. 2020 . Available from: https://om.tele2.se/ny-undersokning-frantele2-och-kantar-sifo-distansarbetet-kommer-oka-med-250efter-pandemin

[22] Arora S, Vyas S. Job satisfaction at the time of COVID-19: An investigation of information technology sector in India. Mukt Shabd J. 2020;4(4):251-63.

[23] Baert S, Lippens L, Moens E, Sterkens P, Weytjens J. The COVID-19 crisis and telework: A research survey on experiences, expectations and hopes [Internet]. Bonn; 2020. Available from: https://www.iza.org/publications/dp/ 13229/the-covid-19-crisis-and-telework-a-research-survey -on-experiences-expectations-and-hopes

[24] Eurofound and ILO. Working anytime, anywhere: The effects on the world of work. Luxembourg and Geneva: Publications Office of the European Union and ILO; 2017.

[25] Messenger JC. Telework in the 21st Century: An Evolutionary Perspective, ILO Future of Work series. Cheltenham, UK and Geneva: Edward Elgar and ILO; 2019.

[26] Eurofound. COVID-19 could permanently change teleworking in Europe | Eurofound [Internet]. 2020. Available from: https://www.eurofound.europa.eu/news/news-articles/covid -19-could-permanently-change-teleworking-in-europe

[27] McCulley L. Lockdown: Homeworkers putting in extra hours - instant messaging up 1900\% [Internet]. 2020. Available from: https://www.thehrdirector.com/business-news/ the-workplace/new-data-over-a-third-38-admit-to-working -longer-hours-when-working-from-home/

[28] Standen P, Daniels K, Lamond D. The home as a workplace: work-family interaction and psychological well-being in telework. J Occup Health Psychol. 1999;4(4):368-81. 
[29] ILO. Teleworking during the COVID-19 pandemic and beyond: A practical guide. Geneva: International Labour Organization; 2020.

[30] Tavares AI. Telework and health effects review. Int J Healthc. 2017;3(2):30.

[31] Sinclair RR, Allen T, Barber L, Bergman M, Britt T, Butler A, et al. Occupational Health Science in the Time of COVID-19: Now more than Ever. Occup Heal Sci. 2020; 4(1-2):1-22.

[32] Rodríguez-Nogueira Ó, Leirós-Rodríguez R, BenítezAndrades JA, Álvarez-álvarez MJ, Marqués-Sánchez P, Pinto-Carral A. Musculoskeletal pain and teleworking in times of the COVID-19: Analysis of the impact on the workers at two Spanish universities. Int J Environ Res Public Health. 2021;18(1):1-12.

[33] Oakman J, Kinsman N, Stuckey R, Graham M, Weale V. A rapid review of mental and physical health effects of working at home: how do we optimise health? BMC Public Health. 2020;20(1):1825.

[34] Tomasini F. Solidarity in the time of COVID-19? Cambridge Q Healthc Ethics. 2020.
[35] Herlitz G. Swedes: What We Are Like and Why We Are As We Are. Uppsala: Uppsala Publishing House AB; 1995.

[36] Barinaga E. Swedishness through lagom: can words tell us anything about a culture [Internet]. Stockholm; 1999. Available from: https://books.google.com/books/about/Swedish ness_Through_Lagom.html?id=xbAzjwEACAAJ

[37] Andreasson U. Trust - the Nordic gold. Copenhagen: Nordic Council of Ministers; 2017.

[38] Holmberg S, Rothstein B. Trusting other people. J Public Aff. 2017;17(1-2):e1645.

[39] Helsingen LM, Refsum E, Gjøstein DK, Løberg M, Bretthauer M, Kalager M, et al. The COVID-19 pandemic in Norway and Sweden - threats, trust, and impact on daily life: a comparative survey. BMC Public Health. 2020;20(1).

[40] Nixona AE, Mazzolab JJ, Bauera J, Kruegerc JR, Spectora PE. Can work make you sick? A meta-analysis of the relationships between job stressors and physical symptoms. Work Stress. 2011;25(1):1-22. 